\title{
Development of Molecular Methods to Detect Macrophomina phaseolina from Strawberry Plants and Soil
}

\author{
Alyssa Burkhardt, Marina L. Ramon, Brett Smith, Steven T. Koike, and Frank Martin ${ }^{\dagger}$
}

First, second, third, and fifth authors: Crop Improvement and Protection Research Unit, United States Department of Agriculture-Agricultural Research Service, Salinas, CA; and fourth author: TriCal Diagnostics, Hollister, CA. Accepted for publication 4 June 2018.

\begin{abstract}
Macrophomina phaseolina is a broad-host-range fungus that shows some degree of host preference on strawberry, and causes symptoms that include crown rot and root rot. Recently, this pathogen has affected strawberry production as fumigation practices have changed, leaving many growers in California and around the world in need of accurate, rapid diagnostic tools for M. phaseolina in soil and infected plants. This study uses next-generation sequencing and comparative genomics to identify a locus that is unique to isolates within a main genotype shared by a majority of isolates that infect strawberry. This locus was used to develop

a quantitative single-tube nested TaqMan polymerase chain reaction assay which is able to quantify as little as 2 to 3 microsclerotia/g of soil with $100 \%$ genotype specificity. An isothermal assay using recombinase polymerase amplification was developed from the same locus and has been validated on over 200 infected strawberry plants with a diagnostic sensitivity of $93 \%$ and a diagnostic specificity of $99 \%$. Together, this work demonstrates the value of using new approaches to identify loci for detection and provides valuable diagnostic tools that can be used to monitor soil and strawberry plant samples for M. phaseolina.
\end{abstract}

Macrophomina phaseolina is a necrotrophic ascomycete fungus that infects over 500 plant species worldwide including soybean, corn, chickpea, and sorghum (Gupta et al. 2012; Islam et al. 2012; Kaur et al. 2012). It commonly causes symptoms that include charcoal rot, crown rot, damping off, stem canker, and dry root rot, all of which can result in severe yield loss and complete death of the plant (Kaur et al. 2012). One identifying characteristic of $M$. phaseolina is its ability to make black, melanized microsclerotia, which are made of 50 to 200 cells and have the ability to survive within the soil for up to 15 years (Gupta et al. 2012; Kaur et al. 2012). Notably, these microsclerotia persist in the soil and germinate in warm temperatures, ranging from 28 to $35^{\circ} \mathrm{C}$ (Mihail 1989; Zveibil et al. 2012). Additionally, the symptoms caused by $M$. phaseolina have been observed to be more severe at higher temperatures on multiple hosts (Mihail 1989; Zveibil et al. 2012).

Previously, M. phaseolina has been identified by plating infected plant material or infested soil on culture media and identifying the distinct fungal characteristics of the pathogen, including its black microsclerotia. Several techniques have been developed for enumeration of soilborne inoculum densities (Cloud and Rupe 1991; Mengistu et al. 2011; Mihail and Alcorn 1982), although these can be time consuming to conduct. In recent years, some species-specific molecular diagnostic tools have been developed to broadly identify the pathogen. Conventional polymerase chain reaction (PCR) markers based on the internal transcribed spacer (ITS) region of the ribosomal DNA (rDNA) were reported by Babu et al. (2007). Species-specific primer sets were developed from a

†Corresponding author: Frank Martin; E-mail: Frank.Martin@ars.usda.gov

Funding: The United States Department of Agriculture California Department of Food and Agriculture Specialty Crop Block Grant Program (grant SCB14052) and the California Strawberry Commission supported this work.

*The $\boldsymbol{e}$-Xtra logo stands for "electronic extra" and indicates that one supplementary figure and two supplementary tables are published online.

This article is in the public domain and not copyrightable. It may be freely reprinted with customary crediting of the source. The American Phytopathological Society, 2018. sequence-characterized amplified region for use with both SYBR green and TaqMan quantitative PCR (qPCR) assays for pathogen detection in soil and infected plants (Babu et al. 2011). In addition, a loop-mediated isothermal amplification assay was developed using the ITS region of $M$. phaseolina to quickly detect the fungus within infected soybean plants (Lu et al. 2015).

Beyond assays for pathogen detection, marker systems to genotype isolates have been reported. Jana et al. (2005a, b) developed both simple sequence repeat (SSR) markers (Jana et al. 2005a) and universal rice primers (URP) (Jana et al. 2005b) in order to genotype different isolates of M. phaseolina while Purkayastha et al. (2006) demonstrated the use of PCR-based markers targeted to the rDNA ITS region to characterize different populations of $M$. phaseolina. Das et al. (2008) also reported on the use of RAPD loci for characterization of isolates, while Reyes-Franco et al. (2006) used amplified fragment length polymorphism analysis and Baird et al. (2010) and Arias et al. (2011) reported on SSR markers.

Despite the general perception that $M$. phaseolina is a broad-hostrange pathogen, there have been reports in the literature suggesting host specialization of isolates. For example, Pearson et al. (1987) observed phenotypic differences between $M$. phaseolina isolates recovered from soybean and corn when grown on media containing chlorate and observed some degree of host preference when isolates of a certain phenotype were grown in association with corn or soybean. When looking at fields that were monocropped to corn, cotton, sorghum, or soybean for 15 years, Su et al. (2001) reported some level of host specialization for isolates recovered from corn and reported that all isolates were grouped according to the host when DNA fingerprint analysis was done using RAPD analysis. Interestingly, isolates exhibited variation in their growth morphology on chlorate medium that reflected a different grouping of isolates within the RAPD analysis grouping for a given host ( $\mathrm{Su}$ et al. 2001).

Recently, M. phaseolina has been identified as a pathogen on strawberry in the United States and in other areas around the world (Avilés et al. 2008; Koike 2008; Jelinski et al. 2017; Mertely et al. 2005; Zveibil et al. 2012). In the United States, the appearance of M. phaseolina on strawberry correlated with phasing out of methyl bromide use in preplant soil fumigation. (Koike et al. 2016, 2013; 
Mertely et al. 2005). Each year, 54,000 acres of strawberry crops are planted in the United States, with a production value of $\$ 1.8$ billion coming from California alone (USDA-NASS 2017). This pathogen has the potential to decrease the yield and profit of this economically important crop, with the most severe symptom being death of the plant. Other symptoms of $M$. phaseolina on strawberry include wilting, stunting, dead leaves, and orange- to brown-colored vascular and cortex tissue within the crown (Koike 2008; Koike et al. 2016). A preliminary analysis of isolates recovered from strawberry plants in California indicates that they show a host preference for strawberry and do not cause disease on common cover crops, including oat and rye; likewise, $M$. phaseolina isolates from other hosts such as melon and apple did not cause disease on strawberry (Koike et al. 2016). Analyses of 15 California isolates using 65 SSR markers of Arias et al. (2011) indicated that, with few exceptions, isolates recovered from strawberry grouped within a single clade (Koike et al. 2016), an observation that has continued when over 460 isolates were genotyped with 24 SSR loci (Marina Ramon, Renee Arias and Frank Martin, personal communication). These strawberry isolates that largely grouped within the same clade are hereafter referred to as those having the main strawberry genotype.

Given the host preference for strawberry exhibited by some isolates of $M$. phaseolina and the grouping of most of these California isolates into a single SSR genotype, it would be advantageous to have the ability to differentiate these isolates from isolates representing other genotypes that don't infect strawberry in order to correctly assess risk to growers. Having a genotype-specific diagnostic marker would facilitate the development of a real-time PCR-based soil quantification similar to the one developed for Verticillium dahliae (Bilodeau et al. 2012). Likewise, the availability of a rapid in-field detection assay would enable diagnosticians to differentiate disease problems associated with $M$. phaseolina from those that have similar symptoms, such as $V$. dahliae and Fusarium oxysporum $\mathrm{f}$. sp. fragariae (Koike et al. 2013). The goals of the work described in this study were to (i) use a comparative genomics approach to identify a locus specific to $M$. phaseolina isolates within the main strawberry genotype; (ii) develop a TaqMan qPCR assay to quantify the main strawberry genotype of $M$. phaseolina in the soil; and (iii) develop a rapid, isothermal recombinase polymerase amplification (RPA) assay to detect M. phaseolina within infected plants using the same approach as reported for other pathogens (Miles et al. 2015; Rojas et al. 2017; Si Ammour et al. 2017).

\section{MATERIALS AND METHODS}

M. phaseolina isolate growth and DNA extraction. Cultures of M. phaseolina $(n=113)$ obtained from various infected hosts collected from California and Arizona were grown on potato dextrose broth at $28^{\circ} \mathrm{C}$ for 4 days. Hyphal mats were removed from the medium, rinsed with sterile water, blotted on paper towels to remove excess liquid, and flash frozen in liquid nitrogen. Following lyophilization, DNA for sequencing was extracted from 10 to $15 \mathrm{mg}$ of hyphal mat tissue. Some DNA for assay development was extracted from blocks of potato dextrose agar covered with M. phaseolina mycelia. DNA was extracted using either the DNeasy Plant Mini kit (Qiagen, Redwood City, CA) or the NucleoSpin Plant II kit (Macherey-Nagel, Düren, Germany). For both kits, an extended incubation time of up to $1 \mathrm{~h}$ was used during the lysis step to increase the overall DNA yield. When using the Macherey-Nagel kit, the following volumes of buffers were used instead of the volumes recommended in the manual for genomic DNA extraction from plants: $600 \mu \mathrm{l}$ of PL1, $625 \mu \mathrm{l}$ of PC, and $600 \mu \mathrm{l}$ of PW1. All DNA was quantified with the Qubit Fluorometer with the Quant-iT dsDNA HS Assay Kit (Invitrogen, Carlsbad, CA). Cultures were stored on dry autoclaved toothpicks colonized by the pathogen in sealed vials kept at room temperature (Delatour 1991). A full list of M. phaseolina isolates that were grown and DNA extracted from cultures as well as DNA received from isolates collected in other states and countries can be found in Supplementary Table S1. DNA from oomycete and other fungal taxa that can be recovered from strawberry and soil were used in the evaluation of specificity.

Illumina sequencing and identification of a strawberry genotype-specific detection locus. With few exceptions, all isolates recovered from diseased strawberry plants were within a single SSR genotype (Koike et al. 2016). Therefore, a comparative genomics approach was used to identify a locus that would be specific for this genotype. Two isolates, one from strawberry (11-12) and the other from alfalfa (13-18), were submitted for a 250-bp paired-end MiSeq run at the United States Department of Agriculture-Agricultural Research Service Genomics and Bioinformatics Research Unit in Stoneville, MS. An additional three isolates from the main strawberry clade and three isolates representing other clades were submitted to the DNA Technologies Core of the University of California, Davis Genome Center for 150-bp paired-end HiSeq sequencing. The 250-bp MiSeq reads for isolate 11-12 were assembled into a draft genome with CLC Genomics Workbench (v. 9; Qiagen) using the default de novo assembly parameters, with $93 \%$ sequence identity and $0.5 \%$ sequence overlap and a minimum contig length of 1,000 bp. All MiSeq and HiSeq reads for isolates that were not in the main strawberry genotype were mapped to this assembly in SeqMan Pro (LaserGene 12; DNASTAR, Madison, WI) with a stringency of $93 \%$ sequence identity and kmer size of 30 nucleotides (nt). Starting with the largest contig, the read coverage report was used to identify and extract regions that were at least $500 \mathrm{bp}$ and had no reads mapping. These extracted sequences were used as the reference sequences for mapping reads from isolates outside of the main strawberry genotype with a stringency of $80 \%$ sequence identity. This was done to determine whether candidate loci were present in the genomes of isolates outside of the main strawberry clade but with a greater level of sequence polymorphism. Regions where no reads mapped were selected for further evaluation. To determine whether these loci were present in other isolates within the main strawberry genotype, reads from each of these isolates were mapped to these templates with a stringency of $93 \%$ sequence identity. Only those regions that were present in all of the main genotype isolates and not present in any form in the isolates outside of the main genotype were retained for further evaluation.

Additional evaluation of specificity was done by establishing BLAST databases in CLC Genomics Workbench for contigs from assembled genomes of each isolate, and the candidate loci were searched against each genome database using BLASTN (Altschul et al. 1990) to ensure that the full-length locus was present in all of the main strawberry genotype isolates and absent in all of the isolates representing other genotypes, as well as to evaluate copy number. Contigs from whole-genome sequencing projects of $M$. phaseolina that were deposited in GenBank were also screened (AHHD01000000 from Bangladesh; LFIX01000000 from India; and LHTM01000000, LHTN01000000, LHTO01000000, LHTP01000000, and LHTQ01000000 from Kansas in the United States). Finally, the candidate loci were searched against the nonredundant DNA database within the National Center for Biotechnology Information using BLASTN (Altschul et al. 1990) and loci that matched any other taxa were discarded. A small number of candidate loci $(n=33)$ that were longer than $500 \mathrm{bp}$ were identified based on a high level of nucleotide sequence conservation ( $>95 \%$ sequence identity) among the main strawberry genotype isolates and the absolute absence of reads mapping or partial BLAST hits from the isolates representing other genotypes.

Designing PCR primers to test the locus with conventional PCR. For five of the candidate loci, PCR primers were designed by selecting regions with a GC content between 40 to $60 \%$, a length of 19 to $23 \mathrm{nt}$, a $3^{\prime}$ end base of a G or C, and a lack of homopolymeric repeats or predicted secondary structure. Only those producing a single, distinct band for the isolates within the main strawberry genotype and no bands for isolates representing 
other genotypes were retained for future assay development. The design and sequence of the primers for the locus selected to detect M. phaseolina from within the main strawberry clade are shown in Figure 1. These primers were each used at a concentration of $400 \mathrm{nM}$ in a $25-\mu \mathrm{l}$ reaction with $2 \mathrm{mM} \mathrm{MgCl} 2,200 \mu \mathrm{M} \mathrm{dNTP}$ (NEB, Ipswich, MA), 1× AmpliTaq PCR buffer (Applied Biosystems, Foster City, CA), and $1 \mathrm{U}$ of AmpliTaq. The cycling parameters used to amplify the PCR product were 1 cycle of $95^{\circ} \mathrm{C}$ for $2 \mathrm{~min} ; 35$ cycles of $95^{\circ} \mathrm{C}$ for $30 \mathrm{~s}, 56^{\circ} \mathrm{C}$ for $30 \mathrm{~s}$, and $72^{\circ} \mathrm{C}$ for $30 \mathrm{~s}$; and a final extension cycle of $72^{\circ} \mathrm{C}$ for $5 \mathrm{~min}$. The products were size confirmed by running a $2 \%$ agarose gel. All DNA samples were tested by amplifying $2 \mathrm{ng}$ of template DNA. To ensure that the quality of DNA was sufficient for amplification, it was tested using $400 \mathrm{nM}$ MpSyK primers (Babu et al. 2011), $2 \mathrm{mM} \mathrm{MgCl} 2,200 \mu \mathrm{M}$ $\mathrm{dNTP}, 1 \times$ AmpliTaq PCR buffer, and $1 \mathrm{U}$ of AmpliTaq in a final volume of $25 \mu \mathrm{l}$. The cycling parameters used were one cycle of $95^{\circ} \mathrm{C}$ for $2 \mathrm{~min} ; 35$ cycles of $95^{\circ} \mathrm{C}$ for $30 \mathrm{~s}, 52^{\circ} \mathrm{C}$ for $30 \mathrm{~s}$, and $72^{\circ} \mathrm{C}$ for $30 \mathrm{~s}$; and a final extension at $72^{\circ} \mathrm{C}$ for $5 \mathrm{~min}$. These products were size confirmed by running a $2 \%$ agarose gel. This primer set is able to amplify all of the genotypes of $M$. phaseolina, confirming that the DNA was of suitable quality for amplification and, therefore, lack of amplification with the Mps primers represented true negative results.

Design of a single-tube nested TaqMan assay. In an effort to enhance the sensitivity of an assay that targets a single-copy nuclear sequence, a single-tube nested qPCR procedure was developed. The design and sequence of the primers used to detect the main strawberry genotype isolates of $M$. phaseolina using the single-tube nested TaqMan qPCR are shown in Figure 1. The full sequence of the locus used to design these primers is shown in Supplementary Figure S1. The internal control (IC) DNA developed by Bilodeau et al. (2012) was also used in this assay at a concentration of approximately $20 \mathrm{fg} / \mu \mathrm{l}$ to monitor for the presence of PCR inhibitors in the qPCR. The IC primer sequence for the forward primer was 5' CGTTTCCCGTTACTCTTCT 3 ' and the sequence for the reverse primer was $5^{\prime}$ GGATTTCGGCCCAG AAACT 3'. The probe used for the IC was 5' Cal Flour Red 610AAAGTAAGCTTATCGATACCGTCGACCT-BHQ2 3' (Bilodeau et al. 2012). Reactions of $25 \mu \mathrm{l}$ were run with $400 \mathrm{nM}$ each of the Mps_TaqMan F and R primers, $400 \mathrm{nM}$ each of the IC F and $\mathrm{R}$ primers, $1 \times$ Perfecta Multiplex qPCR ToughMix (Quantabio, Beverly, MA), $20 \mathrm{nM}$ each of the Mps_TaqMan_External $\mathrm{F}$ and $\mathrm{R}$ primers, $200 \mathrm{nM}$ Mps_TaqMan_probe, $40 \mathrm{nM}$ IC probe, and approximately $20 \mathrm{fg}$ of the IC (Fig. 1). The low concentration of the external primers was experimentally determined to ensure that they were used up in the initial 20 cycles run at the higher annealing temperature so that they would not interfere with subsequent template amplification at a lower annealing temperature. The effect of the IC on $M$. phaseolina target amplification was measured by running the reaction with and without the presence of the IC primers and probe (Fig. 2). DNA samples of 2 ng were used to test the specificity of this assay. All DNA samples were run in duplicate on the plate and the average of the two values was used in calculations for each sample. Standard curves for this assay were produced using

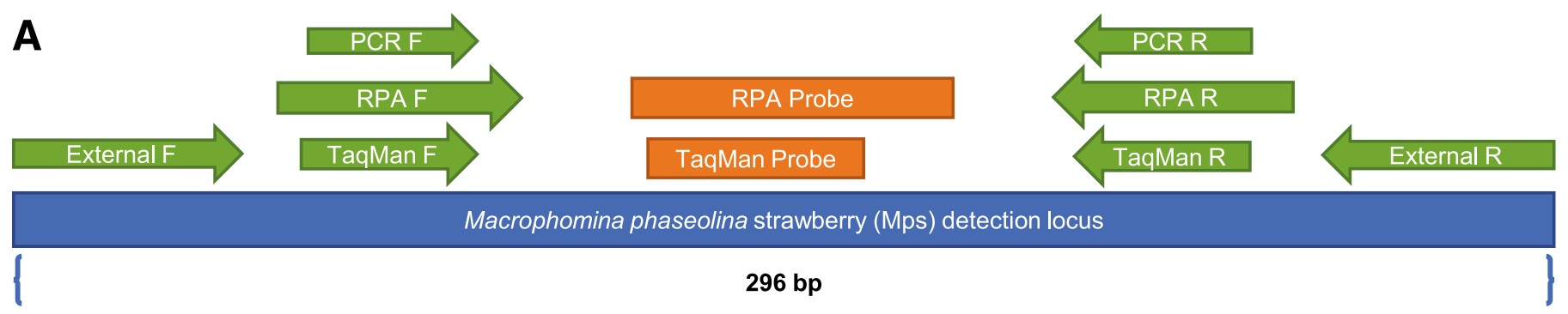

B

\begin{tabular}{|c|c|c|c|}
\hline Primer/Probe Name & Primer Sequence & $\begin{array}{l}\text { Length } \\
\text { (bp) }\end{array}$ & GC \\
\hline Mps_PCR_F & CCTCGGCAAATCCCTATAG & 19 & $53 \%$ \\
\hline Mps_PCR_R & GTTTACCCTCTGTCTATTC & 19 & $42 \%$ \\
\hline Mps_TaqMan_F & CCTCGGCAAATCCCTATAG & 19 & $53 \%$ \\
\hline Mps_TaqMan_External_F & CTAAAGTGGCTTAATACTAATTTAGCGCCGGCGAATC & 37 & $43 \%$ \\
\hline Mps_TaqMan_R & GTTTACССTCTGTCTATTCC & 20 & $45 \%$ \\
\hline Mps_TaqMan_External_R & GTAAGCCTTACCGCACTAGAAGTAAGGGTAAGATCG & 36 & $47 \%$ \\
\hline Mps_TaqMan_probe & $\begin{array}{l}\text { Quasar670- } \\
\text { CTATTTGGTTAACCCCTACTCGCTTAGACT-BHQ2 }\end{array}$ & 30 & $43 \%$ \\
\hline Mps_RPA_F & AGCCTCGGCAAATCCCTATAGCCTCGGTTAAT & 32 & $50 \%$ \\
\hline Mps_RPA_R & $\begin{array}{l}\text { CTAGTTTACCCTCTGTCTATTCCGAATTCTCGGT } \\
\text { CTTCTATTTGGTTAACCCCTACTCGCTTAGAC[T(CAL }\end{array}$ & 34 & $44 \%$ \\
\hline Mps_RPA_probe & $\begin{array}{l}\text { Fluor Red 610][dSpacer]C[T(BHQ-2)] } \\
\text { CTTTACGATTATTATC - Spacer C3 }\end{array}$ & 51 & $37 \%$ \\
\hline
\end{tabular}

Fig. 1. Genotype-specific Macrophomina phaseolina locus with the design and sequences of the primers and probes used for detection. A, Diagram of the location of the primers and probes along the 296-bp detection locus for the polymerase chain reaction (PCR), TaqMan quantitative PCR, and recombinase polymerase amplification (RPA) assays. B, Primer and probe sequences for all assays. Primers were synthesized by Integrated DNA Technologies, Inc., Coralville, IA. Probes were synthesized by Biosearch Technologies, Inc., Novato, CA. GC = guanine-cytosine content, BHQ2 = Black Hole Quencher 2, and dSpacer $=$ tetrahydrofuran (THF). 
DNA prepared from three different strawberry isolates from the main genotype ranging from $50 \mathrm{fg}$ to $2 \mathrm{ng}$ (dilution series of $2 \mathrm{ng}$, $200 \mathrm{pg}, 20 \mathrm{pg}, 2 \mathrm{pg}, 200 \mathrm{fg}, 100 \mathrm{fg}$, and $50 \mathrm{fg}$ ). The average and standard deviation were calculated from these three biological replicates (Fig. 2). To test the ability of this assay to detect M. phaseolina within soil samples, one set of the standard curve samples was also run in the presence of $1 \mu \mathrm{l}$ of a soil DNA extract which did not contain any M. phaseolina DNA (Fig. 2). The qPCR was run in a CFX96 Real-Time PCR Detection System (Bio-Rad Laboratories, Hercules, CA) with nested cycling parameters of 1 cycle of $95^{\circ} \mathrm{C}$ for $3 \mathrm{~min}, 20$ cycles of $95^{\circ} \mathrm{C}$ for $15 \mathrm{~s}$ and $70^{\circ} \mathrm{C}$ for $30 \mathrm{~s}$ with a plate read, followed by 50 cycles of $95^{\circ} \mathrm{C}$ for $15 \mathrm{~s}$ and $62^{\circ} \mathrm{C}$ for $30 \mathrm{~s}$ with a plate read. No fluorescence was observed during the first amplification step of 20 cycles, and the cycle threshold $\left(\mathrm{C}_{t}\right)$ value was taken from the second amplification step of 50 cycles. Nonnested cycling parameters were also tested with 1 cycle of $95^{\circ} \mathrm{C}$ for $3 \mathrm{~min}$ and 50 cycles of $95^{\circ} \mathrm{C}$ for $15 \mathrm{~s}$ and $62^{\circ} \mathrm{C}$ for $30 \mathrm{~s}$ with a plate read. The baseline threshold for each fluorophore was set at 50 . Specificity of the assays was confirmed by using $2 \mathrm{ng}$ of DNA from all isolates and taxa as template.

Soil sample processing and plating for estimating inoculum density. Soil samples were collected from strawberry production fields in Monterey and Ventura counties in California, mixed by hand, and air dried at ambient temperature for 2 weeks. Dried soils were initially ground in a Houghton Manufacturing (Vicksburg, MI) HM-375 soil grinder fitted with a number 35 perforated plate and further pulverized in a mortar and pestle until any remaining clumps were broken apart. After grinding, soil samples were well mixed and subsamples were taken for plating and DNA extraction. Soil samples were plated on Sorenson's NP-10 medium (Kabir et al. 2004; Sorensen et al. 1991) using a modified two-stage cascade air sampler (Tisch TE-10-860,Village of Cleves, OH) to quantify M. phaseolina inoculum density. For each of three replicates per field sample, $0.5 \mathrm{~g}$ of ground soil was plated across six 100-mm Petri plates filled with $23 \mathrm{ml}$ of NP-10 medium. The plates were inverted and incubated in plastic boxes in the dark at $30^{\circ} \mathrm{C}$ for 2 weeks. After incubation, plates were washed by hand under running tap water and examined under a dissecting microscope for the presence of M. phaseolina colonies with microsclerotia. Colonies were enumerated and the mean microsclerotia per gram of soil was calculated from the three replicates of each soil.

DNA extraction from soil samples. For each dried and ground soil sample, DNA from three replicates of 0.5 -g soil samples was extracted using the FastDNA Spin kit for soil (MP Biomedical, Santa Ana, CA), with some modifications. Samples were homogenized using a FastPrep FP120 homogenization instrument (MP Biomedical) for $45 \mathrm{~s}$ at a speed of 6.5 (Bilodeau et al. 2012). Following homogenization, the lysate was centrifuged at $16,000 \times g$ for $10 \mathrm{~min}$ to pellet soil and cellular debris. After the supernatant was transferred to a new tube and the protein precipitation solution (PPS) was added, the tube was inverted 20 times by hand and centrifuged for $5 \mathrm{~min}$ at $16,000 \times g$. Following centrifugation, the supernatant was removed and added to $800 \mu \mathrm{l}$ of binding matrix in a 2-ml Eppendorf tube. Following 5 to $7 \mathrm{~min}$ of binding matrix settling after inversions, $800 \mu \mathrm{l}$ of the supernatant was discarded. The DNA was eluted with $100 \mu \mathrm{l}$ of prewarmed DES (DNase/Pyrogen-Free Water) buffer $\left(65^{\circ} \mathrm{C}\right)$ which was then reapplied to the spin filter a second time to elute the DNA. Finally, $1 \mu \mathrm{l}$ of DNA was used in all detection reactions.

RPA assay. The locus used to detect the main strawberry genotype of $M$. phaseolina by qPCR was also used for the RPA assay with the modified primer and probe sequences shown in Figure 1. The coxl gene-based plant IC from Miles et al. (2015) was used with the forward primer sequence, Cox1_IPC_RPA_F, being 5' CATGCGTGGACCTGGAATGACTATGCATAGA $3^{\prime}$ and the reverse primer sequence, Cox1_IPC_RPA_R, being 5' GGTTGTAT TAAAGTTTCGATCGGTTAATAACA $3^{\prime}$. The probe for the plant IC is GGTCCGTTCTAGTGACAGCATTCCYACTTTTATTA [HEXdT] C [THF] C [BHQ1-dT] YCCGGTACTGGC [3'-C3SPACER].
The TwistAmp exo kit (TwistDx, Cambridge, UK) was used with a final concentration of $300 \mathrm{nM}$ Mac_RPA_F and Mac_RPA_R primers, 250 nM Cox1_IPC_RPA_F and Cox1_IPC_RPA_R primers, 120 $\mathrm{nM}$ each probe, $14 \mathrm{mM}$ magnesium acetate, and $29.5 \mu \mathrm{l}$ of the TwistAmp exo rehydration buffer in a $50-\mu l$ reaction. The reaction was prepared in a PCR strip tube with the master mix (except for the magnesium acetate) and the sample was transferred to the TwistDx reaction tubes with a multichannel pipet. The liquid was mixed with the lyophilized reaction pellet within the TwistDx tubes by pipetting up and down 12 times to thoroughly mix the reaction. A single TwistDx microball was added to each tube to facilitate mixing during amplification. The magnesium acetate solution $(2.5 \mu \mathrm{l})$ was added to the inside of the lids of the strip tube caps and mixed with the rest of the reagents via a short centrifugation step immediately prior to starting the instrument reading. The reaction was run using an Axxin T16-ISO instrument (Fairfield, Australia) with v. 1.8.0.3 software, with the fluorescence channels set at 7\% FAM, $40 \% \mathrm{Hex}$, and $25 \%$ Rox. The instrument was set at $39^{\circ} \mathrm{C}$ for 30 cycles, with each cycle consisting of a 50 -s read period and a 10 -s pause period. The data were analyzed by exporting the readings as an Excel file and calculating the slope as fluorescence signal change over a time period between 5 and $25 \mathrm{~min}$. The cutoff slope values used to determine a positive result were 12 for the plant IC and 6 for M. phaseolina. The onset of amplification was identified as the time (seconds) at which the fluorescence value crossed 500. The log of this value was used to create the standard curves to determine the sensitivity for this assay (Fig. 3). Specificity of the assay was confirmed by using DNA from all isolates and taxa as template.

Strawberry plants were processed for RPA by macerating $0.5 \mathrm{~g}$ of symptomatic crown tissue with $5 \mathrm{ml}$ of $1 \times$ GEB2 buffer (Agdia, Inc., Elkhart, IN) using techniques previously reported (Miles et al. 2015). The extract ( $1 \mu \mathrm{l})$ was used immediately for the assay or the extract was flash frozen and stored at $-80^{\circ} \mathrm{C}$ until it was thawed on ice before use.

\section{RESULTS}

Identification of genotype-specific loci to detect $M$. phaseolina. Candidate loci for the main strawberry genotype were identified using a comparative genomics approach by mapping all reads from the nonstrawberry genotype to a reference sequence of an

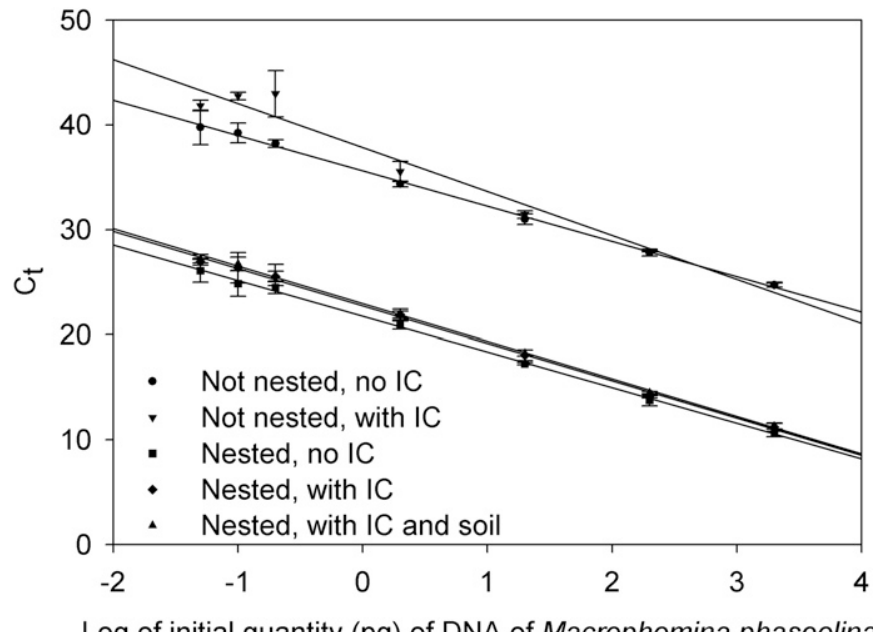

Fig. 2. Genotype-specific TaqMan assay using a serial dilution of purified Macrophomina phaseolina DNA from $2 \mathrm{ng}$ to $50 \mathrm{fg}$ with and without a set of nested primers, an internal control (IC), or soil extract. Three biological replicates of each serial dilution were tested with two technical replicates on each plate which were averaged to give a single value for each biological replicate. Error bars represent the standard deviation from three biological replicates. Only two biological replicates were detected for some samples of a concentration of $100 \mathrm{fg}$ or less 
isolate representing the main strawberry genotype (11-12). Contigs were sorted for size, and the read depth per size of contig was used as a preliminary screen to identify contigs that might contain regions where no reads mapped. The coverage report for the contig was then used to identify and extract these unique sequences. In total, 90 contigs were examined, from which 33 loci were extracted for further evaluation. Following subsequent screening to test that the candidate loci were present in the sequence data from the isolates within the strawberry genotype and a BLAST search (Altschul et al. 1990) against sequences in GenBank, a list of potential candidates to evaluate further was made. Primers were designed for each locus and a panel of 10 different $M$. phaseolina isolates from both inside and outside of the main strawberry genotype were used to evaluate the in silico predictions with PCR. After the initial PCR testing, a single intergenic locus was identified as having the clearest and most robust single product at $175 \mathrm{bp}$. This locus was then evaluated using the optimized PCR assay with a larger panel of nearly 80 isolates representing the main strawberry genotype and other genotypes, and all of the isolates amplified as predicted based on their location within the cladogram of SSR data (data not shown). The final detection locus, which is shown in Figure 1, was then used to develop TaqMan qPCR and isothermal RPA assays.

Development of a single-tube nested TaqMan qPCR assay to detect $M$. phaseolina in soil. A TaqMan qPCR assay was developed that can be used with either just a set of internal primers (Mps_TaqMan_F/R) or a set of external primers and nested internal primers (Fig. 1). The use of a nested amplification increases the sensitivity of the assay, which is important for being able to detect low levels of $M$. phaseolina microsclerotia from DNA extracted from soil. With the addition of the primer pair external to the standard TaqMan amplification primers, the samples with the lowest concentrations were amplified more consistently and with a lower $\mathrm{C}_{\mathrm{t}}$. With a nonnested amplification in the presence of an IC, 200,100 , and $50 \mathrm{fg}$ of $M$. phaseolina DNA purified from fungal cultures was detected with 4 of 6,2 of 6 , and 3 of 6 technical replicates on the plate amplifying, respectively. Adding the external primers for a nested amplification increased the frequency at which the lower amounts of DNA were detected, with 6 of 6, 4 of 6 , and 4 of 6 technical replicates amplifying for 200, 100, and $50 \mathrm{fg}$, respectively. Furthermore, using the single-tube nested approach lowered the $\mathrm{C}_{\mathrm{t}}$ of the target amplicon, with the 50- to 200-fg DNA samples amplifying with a $C_{t}$ of 40 to 43 using a nonnested

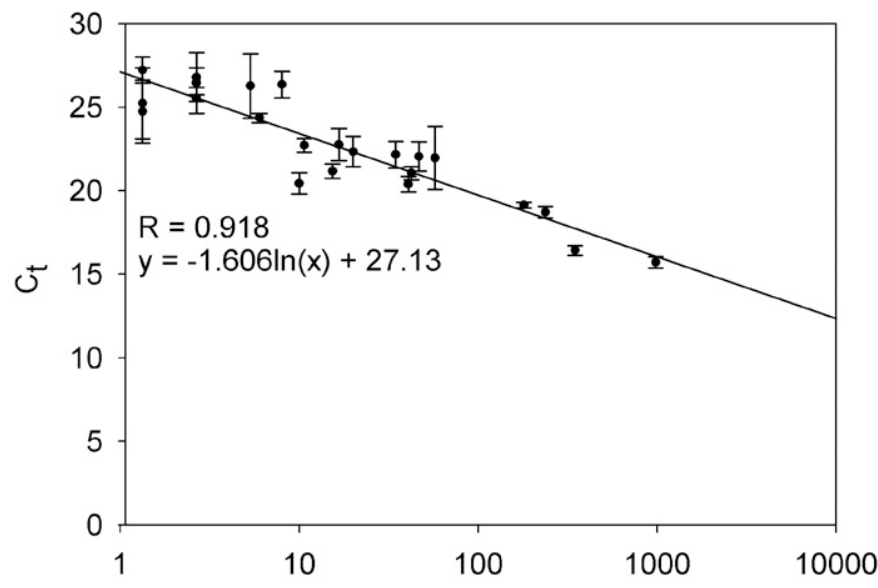

Macrophomina phaseolina microsclerotia per gram of soil

Fig. 3. Correlation of the mean cycle threshold $\left(C_{t}\right)$ value from the nested TaqMan quantitative polymerase chain reaction assay with the internal control (IC) versus the log of the microsclerotia count of Macrophomina phaseolina per gram of soil from soil plating of the same soil samples. DNA from each soil sample was extracted from $0.5 \mathrm{~g}$ of soil in triplicate. Error bars represent the standard deviation of the $\mathrm{C}_{\mathrm{t}}$ values of the three extractions. amplification and amplifying with a $\mathrm{C}_{\mathrm{t}}$ of 25 to 27 with the addition of the nested primers (Fig. 2).

The concentration and length of the external primers was optimized such that no amplification of the product is detected through the probe during the first round of qPCR due to the annealing temperature of the first 20 cycles being higher than the probe annealing temperature. This first step serves to preamplify the low level of target for the next detection step of the qPCR assay. When the temperature of the reaction is lowered by $8^{\circ} \mathrm{C}$ for the second round of qPCR, the internal primers and probe are able to more efficiently bind, and proportionally more product is detected during the second step (Forsman et al. 2003). Overall, the use of the nested set of primers in a single-tube qPCR assay is able to drop the $\mathrm{C}_{\mathrm{t}}$ and allows the target, especially at low concentrations, to be amplified more consistently.

The single-tube nested TaqMan qPCR assay had a detection limit of $50 \mathrm{fg}$ of $M$. phaseolina DNA in a reaction with and without the presence of an IC and soil extract (Fig. 2). The efficiency of the qPCR assay with the nested primers and without the IC was $98.4 \%$ while the efficiency of the assay with the IC and with the IC and in the presence of soil extract was 90.3 and $90.8 \%$, respectively. Although adding the IC decreased the efficiency of the qPCR, it did not affect the detection limit or the rate at which the lowest concentration samples were able to amplify. In this assay, the use of the IC from Bilodeau et al. (2012) amplified at an average $\mathrm{C}_{t}$ of $31.18 \pm 1.89(n=48)$ when considering all of the DNA samples that were used to create the standard curve in the presence of the IC and soil extract. However, the $\mathrm{C}_{\mathrm{t}}$ value of the IC is higher for samples that also have a high concentration of the pathogen target DNA, likely due to competition for amplification-limiting PCR reagents. For example, wells with $200 \mathrm{pg}$ to $2 \mathrm{ng}$ of $M$. phaseolina DNA had an average $\mathrm{IC} \mathrm{C}_{\mathrm{t}}$ of $32.99 \pm 0.78(n=6)$ whereas the rest of the DNA concentrations tested ( $20 \mathrm{pg}$ to $50 \mathrm{fg}$ ) had an average IC $\mathrm{C}_{\mathrm{t}}$ of $30.27 \pm 0.55(n=30)$. Given the amount of M. phaseolina DNA in most of the soil samples tested, the $\mathrm{C}_{\mathrm{t}}$ of the IC averaged $30.19 \pm$ $0.72(n=36)$. Therefore, if the $\mathrm{C}_{\mathrm{t}}$ of the IC is >31.63, PCR inhibitors might be present in the soil sample.

Given the categories of isolates representing the main strawberry genotype and nonstrawberry genotype, the diagnostic specificity and sensitivity for this assay are both $100 \%$. Specifically, 92 isolates from within the main strawberry genotype all tested positive while 61 isolates representing other genotypes all tested negative. Of these, a majority of the isolates tested were from prominent production areas in California; additionally, DNA from isolates in other states, including Arizona and Florida, and other countries, including Spain, Argentina, and Israel, were also tested and the results correlated with their genotypes. In addition, oomycete and other fungal taxa commonly encountered on strawberry plants or in soil representing Pythium, Phytophthora, Fusarium, Verticillium, Penicillium, and Aspergillus spp. were not detected with this assay.

Quantification of M. phaseolina in soil. A key application of the nested TaqMan assay for detection of M. phaseolina is its ability to quantify the pathogen inoculum density in soil; however, before this can be done, the relationship between plate counts and $C_{t}$ must be determined. The exact same aliquot of dried and ground soil was used for soil plating and for DNA extraction. Forty-two soil samples were collected from strawberry production fields in Monterey, Santa Cruz, and Oxnard Counties in California. For the nested qPCR TaqMan assay, DNA from three technical replicates of each of these soils were extracted. Samples from 23 soils that had positive plate counts of the pathogen and DNA amplify from each of the three technical replicates were used in a correlation analysis to compare the plated count of microsclerotia per gram of soil to the average $C_{t}$ value from the three technical replicates of soil (Supplementary Table S2). Overall, this yielded a strong correlation, with an $R$ value of 0.918 (Fig. 3). Of the 42 soils tested, 11 had no microsclerotia present in the soil plating and no 
M. phaseolina detected in the TaqMan assay, which further supports that this assay does not detect other common microflora living in the soil. Five soils had an average of 0.66 microsclerotia $(\mathrm{ms}) / \mathrm{g}$ of soil, and none of these had all three replicates of soil DNA extractions amplify; thus, $<1 \mathrm{~ms} / \mathrm{g}$ of soil is not considered detectable with this assay. Another five soils had an average of $1.33 \mathrm{~ms} / \mathrm{g}$ of soil detected via plating, and three of these soils had all three technical extraction replicates amplify with the qPCR assay. Three soils had an average of $2.66 \mathrm{~ms} / \mathrm{g}$ of soil, and all of these soils had all of the extraction replicates amplify; however, another soil with $3.33 \mathrm{~ms} / \mathrm{g}$ of soil only had two of the three technical replicates of the soil DNA extraction amplify. Some of the inconsistencies in the correlation of plate counts to $C_{t}$ values may also be attributed to high variation in plate count data when few microsclerotia are present. All things considered, the limit of detection for this assay is 2 to $3 \mathrm{~ms} / \mathrm{g}$ of soil, which corresponds with a $C_{t}$ value between 25.4 and 27. For higher count soils, all of the technical replicates of the soil extractions yielded a consistent $C_{t}$ value, as shown by the small error bars representing standard deviation in Figure 3. Overall, the average $\mathrm{IC} \mathrm{C}_{t}$ value for each soil was within an acceptable range that indicated that PCR inhibitors were not present at levels high enough within the soil samples to inhibit amplification.

Development of an RPA assay. The RPA assay developed to detect the main strawberry genotype of $M$. phaseolina used the same locus as the TaqMan assay but had longer primer sequences and different probe modifications to fit the specifications of the RPA assay (Fig. 1). When designing this assay, it was very important to select a locus that was entirely absent in the other genotypes because the RPA assay is more tolerant of polymorphisms in the primer and probe binding sites (Boyle et al. 2013). In this assay, using a presence or absence locus between the target and off-target isolates, we achieved $100 \%$ genotype specificity with DNA isolates from purified M. phaseolina cultures representing genotypes from California and around the world. The assay detected 92 isolates from the main strawberry genotype as positive and did not amplify 61 isolates from outside of the main genotype (Table 1). In addition, representatives of other soil microbes, including those from Fusarium, Pythium, Phytophthora, Verticillium, Aspergillus, and Penicillium spp., were tested and were not detected with this RPA assay.

Although the specificity of this assay was determined using purified DNA from cultured $M$. phaseolina, the ultimate purpose of this assay was to be able to detect the fungus within plant tissue. Therefore, a standard curve was made using purified M. phaseolina DNA in the presence and absence of a crown tissue extract from a healthy plant (Fig. 4). This assay is capable of detecting as little as $200 \mathrm{fg}$ of M. phaseolina DNA even in the presence of crown extract; however, the onset of amplification in the samples with the plant extract was slightly delayed compared with those without the crown extract (Fig. 4). Nevertheless, this does not seem to affect the overall detection limit of the assay.

In addition to being tested with purified DNA, this assay was also extensively tested with infected plant tissue, with $>200$ crowns being assayed in total (Table 2). In the assay development phase, 52 plants were tested from California, with a large portion of these plants coming from Monterey County. Of these plants, 37 tested positive and had symptoms consistent with $M$. phaseolina infection. Some of these plants were cultured to confirm that M. phaseolina could be recovered from the discolored crown and others were taken from fields with previously identified $M$. phaseolina infestations. Of the 52 plants, 15 tested negative, of which 3 were false negatives. For the false-negative samples, many of the issues were likely due to sampling errors such as not collecting tissue from the symptomatic or discolored region of the crown. The other plants that tested negative were confirmed to be negative by culturing or were infected with another genotype of $M$. phaseolina.

Following the initial validation of this assay, the RPA assay was transferred to the University of California Cooperative Extension (UCCE) diagnostic lab in Salinas and was used to test 158 strawberry plants during the 2017 growing season (Table 2). Of these, 27 gave a positive result and 6 were confirmed by culturing $M$. phaseolina from the infected tissue. One plant gave a false positive, which may have occurred if the section of crown that was used for the RPA was infected with $M$. phaseolina while the section of crown used for the plating assay was not. In all, 130 plants tested negative, and 128 of these plants tested positive for another pathogen, including Fusarium, Verticillium, and Cylindrocarpon spp., or had no culturable pathogen.

TABLE 1. Macrophomina phaseolina isolates that were tested in the TaqMan and recombinase polymerase amplification assays to determine assay specificity using $2 \mathrm{ng}$ of purified DNA ${ }^{\mathrm{a}}$

\begin{tabular}{|c|c|c|c|}
\hline Origin host & Location & Year & $\begin{array}{c}\text { Number of } \\
\text { isolates }\end{array}$ \\
\hline
\end{tabular}

Main strawberry genotype:

Test positive

Strawberry

Strawberry

Strawberry

Strawberry

Cantaloupe

Strawberry

Strawberry

Strawberry

Strawberry

Strawberry

Strawberry

Strawberry

Pepper

Strawberry

Strawberry

Strawberry

Strawberry

Strawberry

Strawberry

Almond

Pistachio

Lima Bean

Strawberry

Strawberry

Strawberry

Strawberry

Strawberry

Strawberry

Strawberry

Strawberry

Strawberry

Nonstrawberry genotypes:

Test negative

Watermelon

Strawberry

Thyme

Watermelon

Alfalfa

Almond

Pistachio

Lima Bean

Alfalfa

Melon

Pomegranate

Quince

Sunflower

Almond

Lima bean

Strawberry

Melon

Watermelon

Chia

Strawberry

Strawberry

Sunflower

Soy

Strawberry

Strawberry

\begin{tabular}{|c|c|}
\hline San Diego, CA & 2011 \\
\hline Orange, CA & 2011 \\
\hline Santa Barbara, CA & 2011 \\
\hline Ventura, CA & 2011 \\
\hline Merced, CA & 2011 \\
\hline Monterey, CA & 2011 \\
\hline Ventura, CA & 2012 \\
\hline San Luis Obispo, CA & 2012 \\
\hline Santa Cruz, CA & 2012 \\
\hline Monterey, CA & 2013 \\
\hline Santa Barbara, CA & 2014 \\
\hline Santa Clara CA & 2014 \\
\hline Santa Clara, CA & 2014 \\
\hline Monterey, CA & 2014 \\
\hline Santa Cruz, CA & 2014 \\
\hline Ventura, CA & 2014 \\
\hline Oxnard, CA & 2014 \\
\hline Stanislaus, CA & 2014 \\
\hline San Diego, CA & 2014 \\
\hline Fresno, CA & 2014 \\
\hline Madera, CA & 2014 \\
\hline Santa Clara, CA & 2014 \\
\hline Ventura, CA & 2015 \\
\hline Santa Cruz, CA & 2015 \\
\hline Santa Barbara, CA & 2015 \\
\hline Monterey, CA & 2015 \\
\hline Ventura, CA & 2016 \\
\hline Solano, CA & 2017 \\
\hline Florida & NA \\
\hline Argentina & NA \\
\hline Spain & NA \\
\hline
\end{tabular}

Riverside, CA 201

Sacramento 2011

Imperial, CA 2012

Imperial, CA 2013

Monterey, CA 2013

Butte, CA 2014

Madera, CA 2014

Santa Clara, CA 2014

Imperial, CA 2014

Sacramento, CA 2014

Fresno, CA 2014

Fresno, CA 2014

Imperial, CA 2014

Fresno, CA 2014

Santa Clara, CA 2014

San Luis Obispo, CA 2016

Arizona 2012

Arizona 2013

Arizona 2014

Florida NA

Argentina

Argentina

Argentina

Spain

NA

NA

NA

NA

Israel NA

a Locations within California are specified by county. NA = not available. 
Two of these plants were false negatives, which could again be a sampling issue in which the section of crown used for plating contained M. phaseolina but the section used for RPA did not. It is essential to use this assay with discolored crown tissue and to use the same crown to confirm the assay by plating the infected material. Overall, the $M$. phaseolina RPA assay had a diagnostic sensitivity of 93\% and a diagnostic specificity of $99 \%$ for all of the strawberry plant samples that were tested.

\section{DISCUSSION}

The development of this set of assays to detect M. phaseolina isolates representing the main strawberry genotype demonstrates the power of using next-generation sequencing data to identify unique loci that can detect a set of organisms. This approach is unique in that it used entire genome sequences to identify a unique locus rather than relying on previously identified conserved loci such as ITS or focusing only on the annotated gene sequences (Babu et al. 2007; Withers et al. 2016). It should be noted that a preliminary draft assembly (3,397 contigs with an $\left.\mathrm{N}_{50}=40.6 \mathrm{~kb}\right)$ was used as a template in this study for identification of genotypespecific sequences. $\left(\mathrm{N}_{50}\right.$ is a genome statistic that indicates the

\section{RPA sensitivity of Macrophomina phaseolina detection}

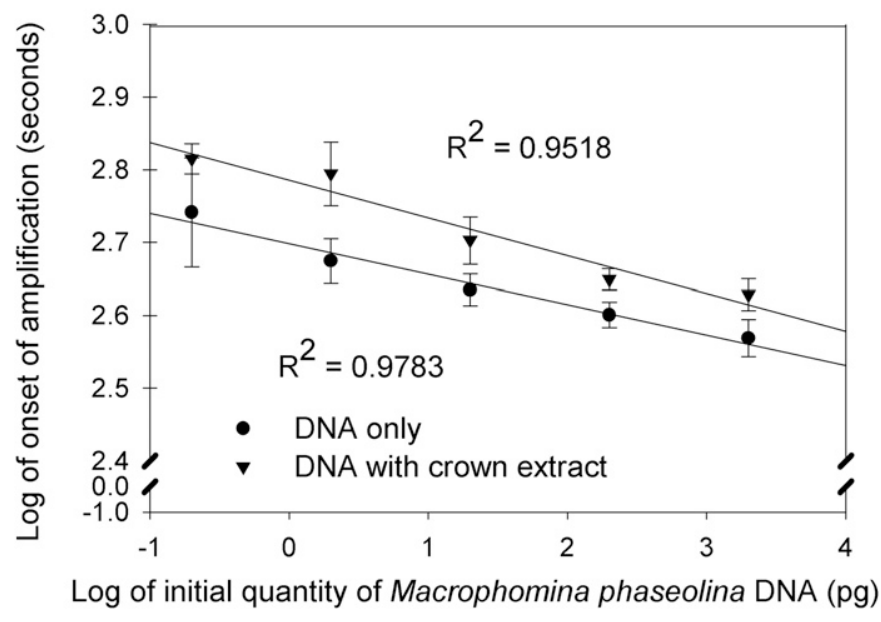

Fig. 4. Onset of amplification of genotype-specific recombinase polymerase amplification (RPA) assay using a serial dilution of purified Macrophomina phaseolina DNA from $2 \mathrm{ng}$ to $0.2 \mathrm{pg}$ with and without a crude strawberry crown extract. Error bars represent the standard deviation from three biological replicates.

TABLE 2. Inventory of symptomatic strawberry plants assayed with the recombinase polymerase amplification assay for Macrophomina phaseolina ${ }^{\text {a }}$

\begin{tabular}{lcl}
\hline Location collected & Number of plants tested & \multicolumn{1}{c}{ Result } \\
\hline Monterey County, CA & 28 & Positive \\
California, unknown county & 7 & Positive \\
San Luis Obispo County, CA & 1 & Positive \\
Ventura County, CA & 1 & Positive \\
Monterey County, CA & 9 & Negative \\
Monterey County, CA & 1 & False negative \\
California, unknown county & 3 & Negative \\
California, unknown county & 2 & False negative \\
UCCE tested, Monterey County & 27 & Positive \\
UCCE tested, Monterey County & 128 & Negative \\
UCCE tested, Monterey County & 2 & False negative \\
UCCE tested, Monterey County & 1 & False positive \\
\hline
\end{tabular}

a An initial subset of the samples in the top half of the table was used for assay development. The second subset in the bottom half of the table consisted of strawberry plants from commercial California fields assayed by the University of California Cooperative Extension (UCCE). Results, especially those that were negative, were frequently confirmed by plating plant tissue. largest contig length that at which using the contigs longer than this accounts for $50 \%$ of the bases in the assembly.) A higher-quality assembly of isolate 11-12, the strawberry genotype isolate, was recently completed $\left(\mathrm{N}_{50}=3.3 \mathrm{Mb}\right.$, BUSCO completeness of $\left.98 \%\right)$ and is currently being annotated (Alyssa Burkhardt, Kevin Childs, and Frank Martin, personal communication). Although this more complete assembly would likely provide additional unique loci as targets for genotype-specific detection, in this study, the lowquality draft assembly provided the necessary resolution for diagnostic development.

In this study, the previous SSR analysis laid the framework for selecting isolates to sequence and compare in order to identify a unique locus because the population structure was well defined for identifying the target and off-target isolates. A large portion of the $M$. phaseolina isolates outside of the main strawberry genotype were recovered from other hosts, including alfalfa, watermelon, and almond. However, several isolates of M. phaseolina that were not in the main strawberry genotype were recovered from strawberry plants. One of nonstrawberry genotype isolates was 11-16, which was recovered from Sacramento in 2011 by Koike et al. (2016) and was found in pathogenicity tests to not be very aggressive on strawberry. Additional isolates recovered from strawberry that were found outside of the main strawberry clade were from other countries, including Argentina, Spain, and Israel, and the virulence of these isolates is unknown. Within the main strawberry genotype, preliminary pathogenicity test data show that some of the isolates that were recovered from nonstrawberry hosts are pathogenic on strawberry while others are not. Additional pathogenicity trials are in progress with nonstrawberry isolates within the main genotype and with strawberry isolates outside of the main genotype to clarify their pathogenicity and virulence. Nevertheless, when considering a majority of the isolates that were examined in this study, and especially considering those from production areas within California, $98 \%$ of the strawberry isolates are located within the main strawberry genotype (M. Ramon, R. Arias, and F. Martin, unpublished) and are detected by this assay whereas other genotypes are not. Furthermore, the high sensitivity and specificity of the RPA assay tested with a large number of symptomatic strawberry plants in California and the high correlation between the soil plating data and the qPCR data from soils collected from strawberry production fields further supports the efficacy of this assay for diagnosing M. phaseolina on strawberry from California and likely from other parts of the world. The observation that other strawberry pathogens and soilborne fungi were not detected by either the TaqMan or RPA assay, as well as the lack of amplification in the TaqMan assay when soils had no detectible $M$. phaseolina in plate assays, further supports assay specificity.

Because the unique locus targeted for the assay was a single-copy nuclear region, it led to some challenges for developing a highly sensitive diagnostic assay for soil samples with highly dispersed M. phaseolina microsclerotia. As a result, a single-tube nested qPCR strategy was developed to quantify $M$. phaseolina in the soil, which led to an improvement in the frequency of detection for some of the lower-concentration DNA samples and lower-microsclerotiacount soils. This assay accurately quantified the amount of $M$. phaseolina in a soil sample compared with the results from soil plating assays and can be used to predict the number of microsclerotia per gram of soil given $\mathrm{C}_{\mathrm{t}}$ value using the equation in Figure 3. The use of the IC is essential for evaluating whether PCR inhibitors in the soil extract are reducing the amplification efficiency, leading to higher $\mathrm{C}_{t}$ for both the IC and the pathogen DNA. Occasionally, a high $\mathrm{C}_{\mathrm{t}}$ for the $\mathrm{IC}$ might be due to competition for PCR reagents when there is a high concentration of pathogen DNA present, as was the case for all of the samples with a high IC $C_{t}$ observed in this study. In cases where different soil types are tested, the presence of a high IC $\mathrm{C}_{\mathrm{t}}$ may indicate the presence of inhibitors in the soil extract, especially when a moderate to high $\mathrm{C}_{\mathrm{t}}$ is observed for the pathogen. In these situations, it may be necessary to use the 
DNA MagaZorb magnetic particles from the Quick Pick kit (BioNobile, Parainen, Finland) after the FastDNA soil extraction protocol to remove inhibitors (Bilodeau et al. 2012).

Given that there is not an effective way to control M. phaseolina on strawberry once the symptoms begin to develop, knowing the risk of M. phaseolina in a field prior to planting is imperative. The qPCR assay has an advantage over soil plating in being able to provide quantitative results within a day from dried and ground soils, whereas the plating assay requires an additional 2 weeks for the fungus to grow. It should be noted that other published techniques for soil plating for enumeration of $M$. phaseolina inoculum density (Cloud and Rupe 1991; Mengistu et al. 2011; Mihail and Alcorn 1982) were found to be unsuccessful when working with infested strawberry soil (data not shown). However, when the UCCE lab was using NP-10 medium for enumeration of $V$. dahliae in field soil, they observed colonies of $M$. phaseolina; subsequent optimization of incubation temperature for growth of $M$. phaseolina was found to work well for using this medium for enumeration of this pathogen.

While collecting soils for this assay, several soils collected from fields with previously identified incidences of $M$. phaseolina disease had little to no microsclerotia counts detected in the soil aliquot that was collected and processed. Therefore, it is critical that future studies look closely into sampling methods used to collect the soil within a given field to ensure that a representative sample is collected that accurately assesses pathogen inoculum. Previous studies have done field-wide surveys for $M$. phaseolina infecting other crops and have found a clustered distribution that varies with both the depth at which the soil was collected and the location where the soil was collected relative to the bed and site of irrigation (Mihail 1989; Young and Alcorn 1984). One of these studies involving Euphorbia lathyris, a plant used to make chemical feedstocks, found that microsclerotia counts of $<1 \mathrm{~ms} / \mathrm{g}$ of soil were sufficient to cause substantial yield loss (Young and Alcorn 1984). The minimum number of microsclerotia per gram of soil that is needed to cause significant yield loss within a strawberry field remains to be determined.

Furthermore, the soils that were quantified with plating and qPCR were processed as quickly as possible after the soils were dried. In some cases, attempting to use both plating and TaqMan methods to retest soils that were stored for several months at room temperature resulted in fewer microsclerotia per gram of soil than originally determined. Previous studies have shown that some decrease in the number or germination of microsclerotia observed over time occurs and is related to many factors, including water potential, temperature, $\mathrm{pH}$, and the presence of other microorganisms (Baird et al. 2003; Olaya and Abawi 1996; Papavizas 1977; Zveibil et al. 2012). The predictive impact of the factors related to the survival of microsclerotia in a given soil sample is not well understood; thus, the proper method of storing soils to maintain expected counts of microsclerotia per gram of soil needs to be determined. As a result, this assay should be used on soil immediately after it has been dried and processed, because prolonged periods of soil storage might result in a lower than expected count of microsclerotia per gram of soil. Future studies will also examine other ways in which the process of drying or processing the soil might be done more quickly or with larger quantities of soil to increase the overall speed and accuracy of the assay. It should also be noted that this assay detects pathogen DNA extracted from the soil but does not distinguish whether the DNA is from a viable microsclerotium; thus, additional work needs to be done to determine the rate of DNA degradation after pathogen management strategies such as soil fumigation have been applied.

In addition to developing an assay that could be used in a field prior to planting, the RPA assay developed in this study provides a quick way to be able to track the current $M$. phaseolina threat by diagnosing diseased plants. Symptomatically, M. phaseolina is difficult to diagnose in the field because its symptoms are similar to those of F. oxysporum f. sp. fragariae and other pathogens that cause wilting. Previously, the plant tissue required plating on media for proper identification, which is time consuming. Unlike other molecular assays such as PCR, RPA has the advantage in that it requires less equipment and sample processing, does not require DNA extraction, tolerates compounds that would inhibit PCR, and is much faster (Miles et al. 2015; Piepenburg et al. 2006). In addition, the real-time fluorescence readout allows this method to be used as a quantitative assay that measures the relative amount of M. phaseolina within an infected tissue. Thus far, all of the plants that have tested positive with this assay have shown clear symptoms of crown discoloration, and samples for both the RPA and tissue plating have been taken from these discolored areas. Additional studies will be done to evaluate the ability of the RPA to detect M. phaseolina in the plants during earlier stages of infection when symptoms may not be apparent. If necessary, future RPA assays could be developed using new approaches that would allow for the detection of single-nucleotide differences for increased specificity (Ng et al. 2017).

In total, this work identifies a locus unique to isolates of M. phaseolina within the main strawberry genotype and uses it in TaqMan qPCR and RPA diagnostic assays for soil and plant tissue, respectively. In the future, the goal is to multiplex markers for additional pathogens in both the TaqMan qPCR and RPA assays. This way, several pathogens that infect strawberry, including $M$. phaseolina, $F$. oxysporum f. sp. fragariae, $V$. dahliae, and Phytophthora spp., could all be detected within the same test. Additional work still needs to be done to understand more about the basic biology and epidemiology of $M$. phaseolina isolates that cause disease in strawberry, including the distribution of microsclerotia within a field and the conditions optimal for $M$. phaseolina microsclerotia longevity and germination. Although a majority of the isolates recovered from strawberry group within a single genotype and some of these were shown to have host preference on strawberry, relatively little work has been directed to understanding the strawberry isolates outside of the main genotype and how their genetic makeup may or may not affect their pathogenicity and virulence. Nevertheless, many of the M. phaseolina isolates and infected plants analyzed in this study came from California, where an extensive strawberry industry is in need of these assays that were shown to be effective in diagnosing M. phaseolina in California.

\section{ACKNOWLEDGMENTS}

We thank S. Mauzey for running the RPA assays at the UCCE. We would also like to thank B. Scheffler, M. Duke, and F. Liu of the USDA-ARS Genomics and Bioinformatics Research Unit in Stoneville, MS for their assistance with getting us started with Illumina sequencing. Mention of trade names or commercial products in this article is solely for the purpose of providing specific information and does not imply recommendation or endorsement by the United States Department of Agriculture (USDA).

\section{LITERATURE CITED}

Altschul, S. F., Gish, W., Miller, W., Myers, E. W., and Lipman, D. J. 1990. Basic local alignment search tool. J. Mol. Biol. 215:403-410.

Arias, R. S., Rayb, J. D., Mengistuc, A., and Schefflera, B. E. 2011. Discriminating microsatellites from Macrophomina phaseolina and their potential association to biological functions. Plant Pathol. 60:709-718.

Avilés, M., Castillo, S., Bascon, J., Zea-Bonilla, T., Martín-Sánchez, P. M., and Pérez-Jiménez, R. M. 2008. First report of Macrophomina phaseolina causing crown and root rot of strawberry in Spain. Plant Pathol. 57:382.

Babu, B. K., Mesapogu, S., Sharma, A., Somasani, S. R., and Arora, D. K. 2011. Quantitative real-time PCR assay for rapid detection of plant and human pathogenic Macrophomina phaseolina from field and environmental samples. Mycologia 103:466-473.

Babu, B. K., Saxena, A. K., Srivastava, A. K., and Arora, D. K. 2007. Identification and detection of Macrophomina phaseolina by using speciesspecific oligonucleotide primers and probe. Mycologia 99:797-803. 
Baird, R. E., Wadl, P. A., Allen, T., McNeill, D., Wang, X., Moulton, J. K., Rinehart, T. A., Abbas, H. K., Shier, T., and Trigiano, R. N. 2010. Variability of United States isolates of Macrophomina phaseolina based on simple sequence repeats and cross genus transferability to related genera within Botryosphaeriaceae. Mycopathologia 170:169-180.

Baird, R. E., Watson, C. E., and Scruggs, M. 2003. Relative longevity of Macrophomina phaseolina and associated mycobiota on residual soybean roots in soil. Plant Dis. 87:563-566.

Bilodeau, G. J., Koike, S. T., Uribe, P., and Martin, F. N. 2012. Development of an assay for rapid detection and quantification of Verticillium dahliae in soil. Phytopathology 102:331-343.

Boyle, D. S., Lehman, D. A., Lillis, L., Peterson, D., Singhal, M., Armes, N., Parker, M., Piepenburg, O., and Overbaugh, J. 2013. Rapid detection of HIV-1 proviral DNA for early infant diagnosis using recombinase polymerase amplification. MBio 4:e00135-e13.

Cloud, G. L., and Rupe, J. C. 1991. Comparison of three media for enumeration of sclerotia of Macrophomina phaseolina. Plant Dis. 75:771-772.

Das, I. K., Fakrudin, B., and Arora, D. K. 2008. RAPD cluster analysis and chlorate sensitivity of some Indian isolates of Macrophomina phaseolina from sorghum and their relationship with pathogenicity. Microbiol. Res. 163:215-224.

Delatour, C. 1991. A very simple method for long-term storage of fungal cultures. Eur. J. Forest Pathol. 21:444-445.

Forsman, A., Uzameckis, D., Ronnblom, L., Baecklund, E., Aleskog, A., and Bindra, A. 2003. Single-tube nested quantitative PCR: A rational and sensitive technique for detection of retroviral DNA. Application to RERVH/HRV-5 and confirmation of its rabbit origin. J. Virol. Methods 111:1-11.

Gupta, G. K., Sharma, S. K., and Rameke, R. 2012. Biology, epidemiology and management of the pathogenic fungus Macrophomina phaseolina (Tassi) Goid with special reference to charcoal rot of soybean. J. Phytopathol. 160:167-180.

Islam, M. S., Haque, M. S., Islam, M. M., Emdad, E. M., Halim, A., and Md, Q. 2012. Tools to kill: Genome of one of the most destructive plant pathogenic fungi Macrophomina phaseolina. BMC Genomics 13:493-509.

Jana, T., Sharma, T. R., and Singh, N. K. 2005a. SSR-based detection of genetic variability in the charcoal rot pathogen Macrophomina phaseolina. Mycol. Res. 109:81-86.

Jana, T. K., Singh, N. K., Koundal, K. R., and Sharma, T. R. 2005b. Genetic differentiation of charcoal rot pathogen, Macrophomina phaseolina, into specific groups using URP-PCR. Can. J. Microbiol. 51:159-164.

Jelinski, N., Broz, K., Jonkers, W., Ma, L.-J., and Kistler, H. C. 2017. Effector gene suites in some soil isolates of Fusarium oxysporum are not sufficient predictors of vascular wilt in tomato. Phytopathology 107:842-851.

Kabir, Z., Bhat, R. G., and Subbarao, K. V. 2004. Comparison of media for recovery of Verticillium dahliae from soil. Plant Dis. 88:49-55.

Kaur, S., Dhillon, G. S., Brar, S. K., Vallad, G. E., Chand, R., and Chauhan, V. B. 2012. Emerging phytopathogen Macrophomina phaseolina: Biology, economic importance and current diagnostic trends. Crit. Rev. Microbiol. 38:136-151.

Koike, S. T. 2008. Crown rot of strawberry caused by Macrophomina phaseolina in California. Plant Dis. 92:1253.

Koike, S. T., Arias, R. S., Hogan, C. S., Martin, F. N., and Gordon, T. R. 2016. Status of Macrophomina phaseolina on strawberry in California and preliminary characterization of the pathogen. Int. J. Fruit Sci. 16:148-159.

Koike, S. T., Gordon, T. R., Daugovish, O., Ajwa, H., Bolda, M., and Subbarao, K. 2013. Recent developments on strawberry plant collapse problems in California caused by Fusarium and Macrophomina. Int. J. Fruit Sci. 13:76-83.

Lu, C., Song, B., Zhang, H., Wang, Y., and Zheng, X. 2015. Rapid diagnosis of soybean seedling blight caused by Rhizoctonia solani and soybean charcoal rot caused by Macrophomina phaseolina using LAMP assays. Phytopathology 105:1612-1617.

Mengistu, A., Smith, J. R., Ray, J. D., and Bellaloui, N. 2011. Seasonal progress of charcoal rot and its impact on soybean productivity. Plant Dis. 95:1159-1166.
Mertely, J., Seijo, T., and Peres, N. 2005. First report of Macrophomina phaseolina causing a crown rot of strawberry in Florida. Plant Dis. 89: 434.

Mihail, J. D. 1989. Macrophomina phaseolina: Spatio-temporal dynamics of inoculum and of disease in a highly susceptible crop. Phytopathology 79: 848-855

Mihail, J. D., and Alcorn, S. M. 1982. Quantitative recovery of Macrophomina phaseolina sclerotia from soil. Plant Dis. 66:662-663.

Miles, T. D., Martin, F. N., and Coffey, M. D. 2015. Development of rapid isothermal amplification assays for detection of Phytophthora species in plant tissue. Phytopathology 105:265-278.

Ng, B. Y. C., Wee, E. J. H., Woods, K., Anderson, W., Antaw, F., and Tsang, H. Z. H. 2017. Isothermal point mutation detection: Toward a first-pass screening strategy for multidrug-resistant tuberculosis. Anal. Chem. 89: 9017-9022.

Olaya, G., and Abawi, G. 1996. Effect of water potential on mycelial growth and on production and germination of sclerotia of Macrophomina phaseolina. Plant Dis. 80:1347-1350.

Papavizas, G. C. 1977. Some factors affecting survival of sclerotia of Macrophomina phaseolina in soil. Soil Biol. Biochem. 9:337-341.

Pearson, C. A. S., Leslie, J. F., and Schwenk, F. W. 1987. Host preference correlated with chlorate resistance in Macrophomina phaseolina. Plant Dis. $71: 828-831$

Piepenburg, O., Williams, C. H., Stemple, D. L., and Armes, N. A. 2006. DNA detection using recombination proteins. PLoS Biol. 4:e204.

Purkayastha, S., Kaur, B., Dilbaghi, N., and Chaudhury, A. 2006. Characterization of Macrophomina phaseolina, the charcoal rot pathogen of cluster bean, using conventional techniques and PCR-based molecular marker. Plant Pathol. 55:106-116.

Reyes-Franco, M. C., Hernandez-Delgado, S., Beas-Fernandez, R., MedinaFernandez, M., Simpson, J., and Mayek-Perez, N. 2006. Pathogenic and genetic variability within Macrophomina phaseolina from Mexico and other countries. J. Phytopathol. 154:447-453.

Rojas, J. A., Miles, T. D., Coffey, M. D., Martin, F. N., and Chilvers, M. I. 2017. Development and application of qPCR and RPA genus- and speciesspecific detection of Phytophthora sojae and P. sansomeana root rot pathogens of soybean. Plant Dis. 101:1171-1181.

Si Ammour, M., Bilodeau, G., Tremblay, D. M., Van der Heyden, H., Yaseen, T., and Varvaro, L. 2017. Development of real-time isothermal amplification assays for on-site detection of Phytophthora infestans in potato leaves. Plant Dis. 101:1269-1277.

Sorensen, L. H., Schneider, A. T., and Davis, J. R. 1991. Influence of sodium polygalacturonate sources and improved recovery of Verticillium spp. from soil. (Abstr.) Phytopathology 81:1347.

Su, G., Suh, S.-O., Schneider, R. W., and Russin, J. S. 2001. Host specialization in the charcoal rot fungus, Macrophomina phaseolina. Phytopathology 91:120-126.

USDA-NASS. 2017. Noncitrus Fruits and Nuts 2016 Summary. Online publication. United States Department of Agriculture National Agricultural Statistics Service. https://www.nass.usda.gov/Publications/Todays_Reports/ reports/ncit0617.pdf

Withers, S., Gongora-Castillo, E., Gent, D., Thomas, A., Ojiambo, P. S., and Quesada-Ocampo, L. M. 2016. Using next-generation sequencing to develop molecular diagnostics for Pseudoperonospora cubensis, the cucurbit downy mildew pathogen. Phytopathology 106:1105-1116.

Young, D. J., and Alcorn, S. M. 1984. Latent infection of Euphorbia lathyris and weeds by Macrophomina phaseolina and propagule populations in Arizona field soil. Plant Dis. 68:587-589.

Zveibil, A., Mor, N., Gnayem, N., and Freeman, S. 2012. Survival, hostpathogen interaction, and management of Macrophomina phaseolina on strawberry in Israel. Plant Dis. 96:265-272. 